\title{
PEMANFAATAN JARINGAN NIRKABEL DI KAMPUS SEKOLAH TINGGI TEKNOLOGI ADISUTJIPTO UNTUK KOMUNIKASI RADIO DUA ARAH PADA SMARTPHONE BERBASIS ANDROID
}

\author{
Hero Wintolo ${ }^{1}$, Basuki Nugroho Susanto ${ }^{2}$ \\ Departemen Informatika \\ Sekolah Tinggi Teknologi Adisutjipto Yogyakarta \\ Jl. Janti, Blok-R, Lanud Adisucipto Yogyakarta \\ Email : ${ }^{1}$ herowintolo@stta.ac.id, ${ }^{2}$ basukinugrohosusanto@gmail.com
}

\begin{abstract}
The importance of communication increases development of information and communication technology in world so rapidly, especially in telecommunications equipment. Mobile phone or smart phone is one type of communication tools that provide communication services to a wide range of features offered but the services offered are not free. Handy Talky is applications and services to communicate for free with the use of smart phones based on Android and has a wifi enable this feature. This communication utilizing wifi network at a frequency of $2.4 \mathrm{GHz}$ as to communication network. Test the application is done by trying on some of the features on a smart phone application with different specifications. From the test produced a smart phone that can run the application properly in some smart phones with Android operating system version 4.2 and above, and the smartphone is connected to a wifi network.
\end{abstract}

Keywords : smart phone, communication, networking, Wifi.

1. Pendahuluan

Komunikasi suara yang dilakukan antar manusia saat ini dapat dilakukan secara audio, teks dan video. Komunikasi tersebut dapat dilakukan secara langsung tanpa jarak atau dengan jarak yang cukup dekat dalam satuan meter hingga jarak dengan satuan puluhan kilometer. Jarak yang cukup jauh dengan indikator puluhan kilometer tersebut membuat manusia dalam berkomunikasi membutuhkan peralatan tambahan. Dengan menggunakan telepon tanpa kabel atau lebih dikenal sebagai telepon seluler atau smartphone sebagai alat untuk berkomunikasi, manusia tetap dapat berkomunikasi menggunakan teks, audio dan video. Secara proyeksi sejumlah

426.520.331 orang [1] yang memberikan sebuah asumsi bahwa setiap rakyat Indonesia minimal memiliki 2 buah smartphone.

Smartphone dengan jumlah sebesar itu digunakan untuk berkomunikasi secara teks, audio dan video menggunakan aplikasi tertentu dan provider telekomunikasi yang mendukung untuk kegiatan tersebut. Provider telekomunikasi tentu akan memberikan layanan sesuai dengan produkproduk yang mereka tawarkan dan biaya yang cukup bervariasi. Salah satu produk yang paling banyak digunakan masyarakat internet dalam bentuk konten yang datanya dapat dilihat pada tabel 1. 
Tabel 1 Jumlah Pengguna Internet di Indonesia (Sumber http://www.internetworldstats.com/asia/id.htm)

\begin{tabular}{|l|r|c|c|c|r|}
\hline Tahun & \multicolumn{1}{|c|}{ Pengguna } & Populasi & \multicolumn{1}{c|}{$\%$} & \multicolumn{1}{c|}{ GDP } & Sumber \\
\hline 2000 & $2,000,000$ & $206,264,595$ & $1.0 \%$ & US\$ 570 & $\underline{\text { ITU }}$ \\
\hline 2007 & $20,000,000$ & $224,481,720$ & $8.9 \%$ & US $\$ 1,916$ & $\underline{\text { ITU }}$ \\
\hline 2008 & $25,000,000$ & $237,512,355$ & $10.5 \%$ & US\$2,238 & $\underline{\text { APJII }}$ \\
\hline 2009 & $30,000,000$ & $240,271,522$ & $12.5 \%$ & US\$ 2,329 & $\underline{\underline{\text { ITU }}}$ \\
\hline 2010 & $30,000,000$ & $242,968,342$ & $12.3 \%$ & US $\$ 2,858$ & $\underline{\text { ITU }}$ \\
\hline 2016 & $88,000,000$ & $258,316,051$ & $34.1 \%$ & US\$ 3,650 & $\underline{\text { APJII }}$ \\
\hline
\end{tabular}

Salah satu penggunaan internet yang disediakan oleh provider tersebut untuk menjalankan sebuah aplikasi zello. Aplikasi ini digunakan untuk komunikasi audio dan gambar dengan menggunakan jaringan internet sebagai penghubungnya. Cara komunikasi audio dengan Push To Talk(PTT) mirip peralatan telekomunikasi Handy Talky (HT) atau Walky Talky (WT). Aplikasi Zello Walkie Talkie dipilih oleh sopir taksi online di Kota Bandung dikarenakan penggunaannya yang mudah (user friendly), tidak memerlukan alat tambahan karena dapat langsung diinstall pada perangkat smartphone yang mereka miliki, dan tidak diperlukan biaya tambahan untuk penggunaan aplikasi tersebut[2].

Penggunaan internet untuk komunikasi PTT ini tidak mutlak, karena selain internet, jaringan Wireless Fidelity (WiFi) dapat digunakan sebagai media penghubungnya. Dengan WiFi pengguna dapat menjalankan aplikasi yang terhubung ke jaringan lokal serta jaringan internet secara gratis dengan ketentuan yang berlaku pada penyedia layanan ini. Komunikasi menggunakan gelombang radio seperti HT yaitu layanan jaringan berupa suara real time melalui layanan IP address (internet protocol address) yang dijalankan dengan data paket. PTT memberikan komunikasi suara langsung dengan seijin operator jaringan. Penggunaan frekuensi komunikasi ini sebelumnya tidak gratis, tetapi berbayar dan biayanya ditanggung oleh negara yaitu pada frekuensi $2.4 \mathrm{Ghz}$. Dengan memanfaatkan frekuensi tersebut pada area internet tanpa kabel atau
WiFilayanan PTT dibuat menggunakan perangkat lunak yang dapat dijalankan pada Android. Komunikasi yang menggunakan PTT bersifat broadcast, artinya seseorang yang sedang berbicara akan dapat didengarkan pembicaraanya oleh semua orang yang saat itu menggunakan perangkat keras dan perangkat lunak serta jaringan $\mathrm{WiFi}$ yang sama. Hal ini menjadi tantangan tersendiri karena komunikasi PTT yang dibangun dengan perangkat lunak Android dengan menggunakan port terbuka untuk komunikasi.

2. Metode Penelitian

2.1 Metode Pengumpulan Data

Penelitian ini diawali dengan melakukan pengumpulan data pendukung untuk merancang sebuah perangkat lunak yang dapat digunakan sesuai dengan tujuannya, salah satu metode yang dapat menunjang penelitian ini yaitu mengumpulkan data dalam bentuk pustaka berupa buku teks dan jurnal penelitian. Dalam penilitian ini, aplikasi yang dirancang dan dibuat mengacu pada buku teks yang membahasa tentang android dan mobile programming. Sedangkan pustaka dalam bentuk jurnal digunakan untuk merancang hubungan antara aplikasi dengan media penyimpan yang tersimpan di internet dan acuan dalam penulisan jurnal.

\subsection{Perancangan Perangkat Lunak}

Perancangan perangkat lunak yang digunakan pada penelitian ini membutuhkan perangkat keras computer serta beberapa 
perangkat lunak yang mendukungnya, rinciannya adalah sebagai berikut :

1. Hardware Komputer
a) Processor Core i3 2,2 Ghz
b) $R A M 6 G B$
c) $H D D 500 G B$
d) Video Card 2 GB gforce GT520M

2. Hardware Smartphone
a) Prosessor Octa Core $1.3 \mathrm{Ghz}$
b) $R A M 1 G B$
c) Grafic Snapdragon $1 \mathrm{Ghz}$
d) Micro SD $4 G B$

3. Software Komputer

a) Sistem operasi Windows 864 bit, digunakan untuk menjalankan aplikasi sebagai pendukung aplikasi lainnya agar dapat digunakan

b) IDE Eclipse Indigo, digunakan untuk merancang perangkat lunak dari tampilan dan sistem yang akan dibuat.

4. Software Smartphone

Android platform 4.3 (Jelly bean) adalah sistem operasi smartphone yang digunakan sebagai batas minimal yang digunakan sebagai sistem pendukung aplikasi lainnya agar dapat berjalan dengan normal.

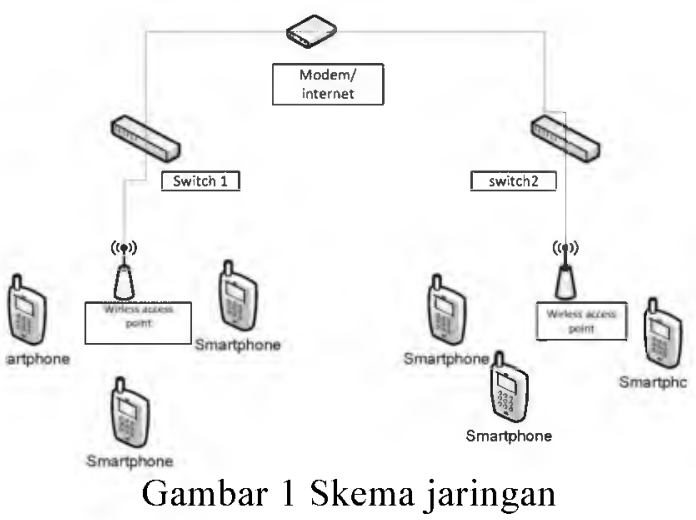

\subsubsection{Skema Jaringan}

Pada implementasi aplikasi HT dapat digunakan pada sebuah jaringan local Area Network (LAN) . Skema jaringan LAN dapat dilihat pada gambar 1. Dari skema jaringan dapat dijelaskan bahwa pada sebuah modem dikoneksikan terhadap dua buah access point dengan network yang sama, pada saat smartphone terkoneksi pada jaringan maka smartphone akan mendapatkan sebuah IP address yang dirancang secara DHCP (Dynamic Configuration Protocol) pada modem, maka komunikasi HT dapat dilakukan antar smartphone.

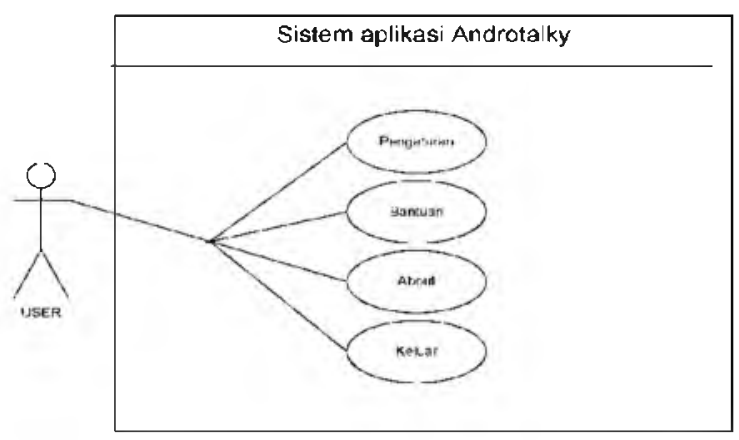

Gambar 2 Diagram Use Case Androtalky

\subsubsection{Diagram Use Case}

Use case diagram menggambarkan fungsional yang diharapkan dari sebuah sistem yang ditekankan adalah "apa" yang dibuat oleh sistem, dan bukan "bagaimana". Sebuah use case mempresentasikan intraksi antara aktor dengan sistem, berikut adalah perancangan use case dapat dilihat pada gambar 2 .

\subsubsection{Class Diagram}

Definisi Class diagram adalah adalah kumpulan objek-objek dengan dan yang mempunyai struktur umum, behavior umum, relasi umum, dan semantic/kata yang umum. Class-class ditentukan/ditemukan dengan cara memeriksa objek-objek dalam sequence diagram dan collaboration diagram. Sebuah class digambarkan seperti sebuah bujur sangkar dengan tiga bagian ruangan. Class sebaiknya diberi nama menggunakan kata benda sesuai dengan domain/bagian/kelompoknya [5]. Berikut adalah class diagram dari aplikasi Androtalk dapat dilihat pada gambar 3 . 


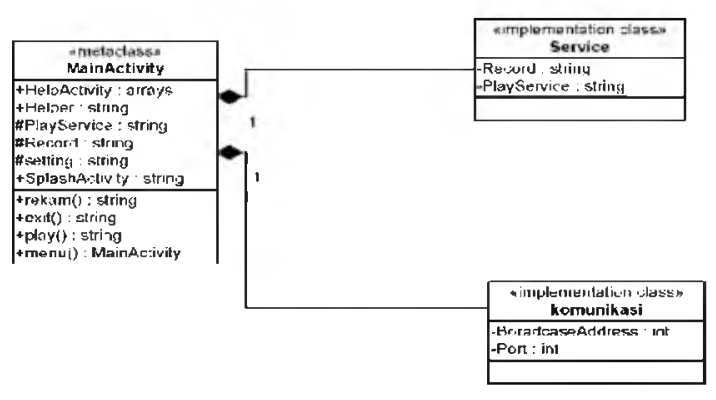

Gambar 3 Class Diagram Androtalky

Pada gambar 3.3 merupakan Deskripsi kelompok obyek-obyek dengan property, perilaku (operasi) dan relasi yang sama. Sehingga dengan adanya class diagram dapat memberikan pandangan global atas sebuah sistem. Hal tersebut tercermin dari class-class yang ada dan relasinya satu dengan yang lainnya. Sebuah sistem biasanya mempunyai beberapa class diagram. Class diagram sangat membantu dalam visualisasi struktur kelas dari suatu system.

\subsubsection{Diagram Aktifitas}

Activity diagram menggambarkan berbagai alir aktivitas dalam sistem yang sedang dirancang, bagaimana masingmasing alir berawal, decision yang mungkin terjadi, dan bagaimana mereka berakhir. Pada bagian ini akan digambarkan dokumentasi pemberian alamat jaringan pada sistem yang bertujuan untuk pemberian identitas.

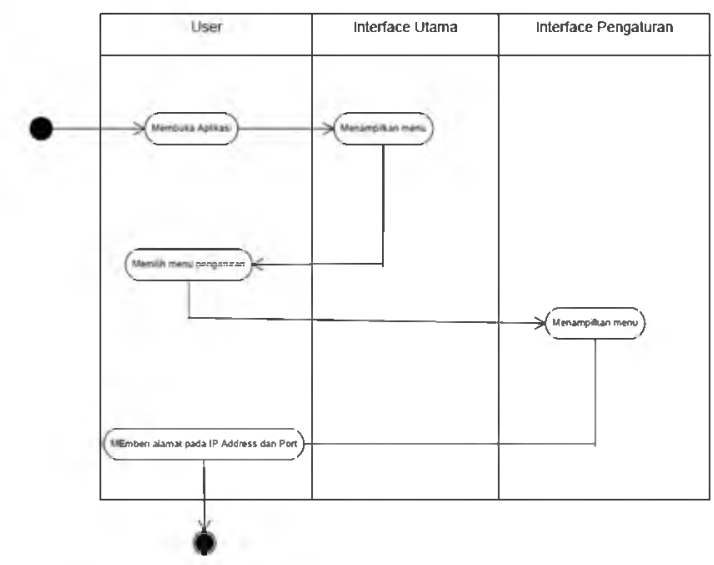

Gambar 4 Diagram Aktifitas pemberian alamat jaringan

Pada diagram aktifitas yang terdapat pada gambar 4 dijelaskan user melakukan pemberian alamat jaringan pada sistem yang akan digunakan, pemberian alamat jaringan bertujuan untuk menyesuaikan alamat jaringan untuk berkomunikasi.

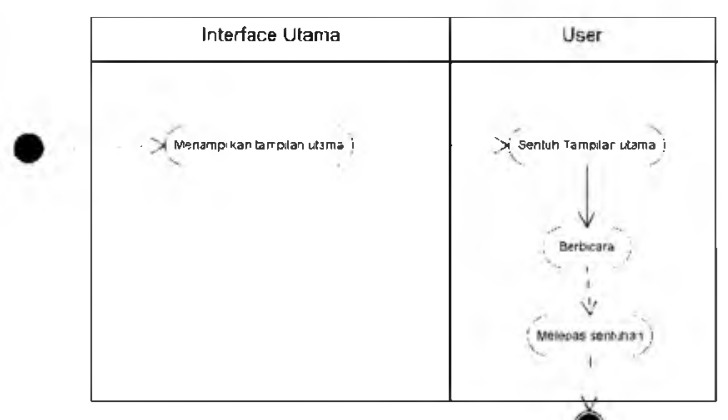

Gambar 5 Diagram aktifitas mengirim suara

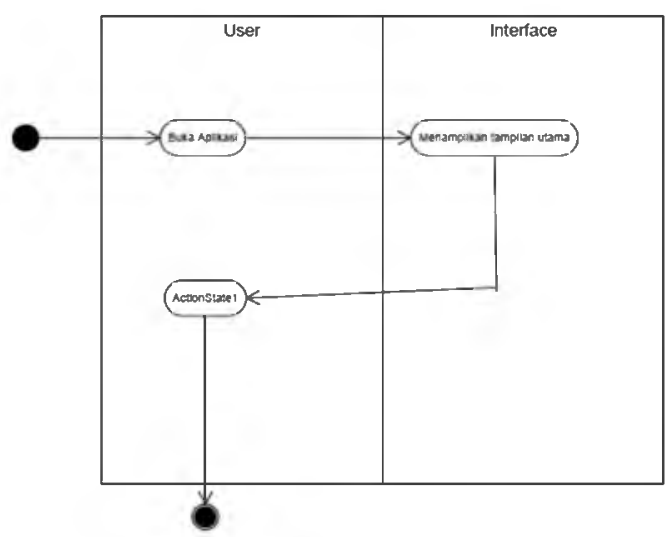

Gambar 6 Diagram aktifitas mendengarkan Diagram aktifitas pada gambar 5 dijelaskan bagaimana melakukan komunikasi saat mengirimkan suara. pada saat user akan berbicara maka user menekan tampilan utama sistem kemudian berbicara, setelah selesai berbicara maka lepaskan tekanan pada layar sehingga akan terkirim suara yang user ucapkan. Dijelaskan pada diagram pada gambar 6 saat user membuka aplikasi maka akan muncul menu utama, maka aplikasi sudah masuk pada mode mendengarkan.

3. Pengujian dan Pembahasan

\subsection{Pengujian Aplikasi}

Setelah melalui tahap perancangan aplikasi, maka selanjutnya aplikasi tersebut diujikan dalam sebuah pengujian. Ada tiga kondisi yang dibuat untuk menguji aplikasi ini, yang pertama diuji pada jaringan Local 
Area Network (LAN) yang memiliki dua alamat jaringan yang berbeda, kondisi pengujian yang kedua dengan menggunakan jaringan $\mathrm{WiFi} \mathrm{LAN}$, dan yang ketiga menguji pada jaringan WiFi yang dihubungkan melalui jaringan internet. Sebelum ketiga pengujian itu dilakukan, pada atahap awal dilakukan pengetesan terhadap Smartphone (S) yang dapat digunakan dengan indikator perangkat lunak yang dirancang dapat dipasang atau diinstall-kan pada peralatan tersebut. Hasil dari pengetesan ini dapat dilihat pada table 2.

Tabel 2 Hasil pengujian smartphone

\begin{tabular}{|c|c|c|c|c|c|c|c|}
\hline \multirow[t]{2}{*}{ No } & \multirow[t]{2}{*}{ Device } & \multirow[t]{2}{*}{ Merk } & \multirow[t]{2}{*}{ OS } & \multicolumn{3}{|c|}{$\begin{array}{l}\text { Fitur } \\
\text { Menu }\end{array}$} & \multirow[t]{2}{*}{ Ket } \\
\hline & & & & & $\mathrm{M}$ & $\mathrm{S}$ & \\
\hline 1 & $\mathrm{~S} 1$ & HP Voice TAB 7 & Kitkat & & $\sqrt{ }$ & $\sqrt{ }$ & Baik \\
\hline 2 & $\mathrm{~S} 2$ & Lenovo A930 & Kitkat & $\sqrt{1}$ & $\sqrt{ }$ & $\sqrt{ }$ & Baik \\
\hline 3 & S3 & Evercross a 71 & Jellybean & $\sqrt{1}$ & $\sqrt{ }$ & $\sqrt{ }$ & Baik \\
\hline 4 & S4 & Lenovo A516 & Jellybean & $\sqrt{ }$ & $\sqrt{ }$ & $\sqrt{ }$ & Baik \\
\hline 5 & S5 & Sony xperia z ultra & Kitkat & & $\sqrt{ }$ & $\sqrt{ }$ & Baik \\
\hline
\end{tabular}

Keterangan gambar :

$$
\begin{aligned}
& \square \quad \mathrm{W}=\mathrm{WiFi} \\
& \square \quad \mathrm{M}=\text { Mikropon } \\
& \square \quad \mathrm{S}=\text { Speaker }
\end{aligned}
$$

Pada pengujian yang pertama dengan menggunakan perangkat yang digunakan untuk jaringan Wifi dengan DHCP IP address. Skema jaringan yang digunakan dapat dilihat pada gambar 7 bahwa jaringan tersebut berada dalam satu network yang memiliki dua buah switch dan dua buah Wireless Access Point (WAP) kemudian smartphone yang sudah terinstal aplikasi Androtalky dengan cara menghubungkan smartphone ke jaringan melalui Wifi kemudian menentukan broadcast address dan port maka aplikasi Androtalky dapat digunakan.

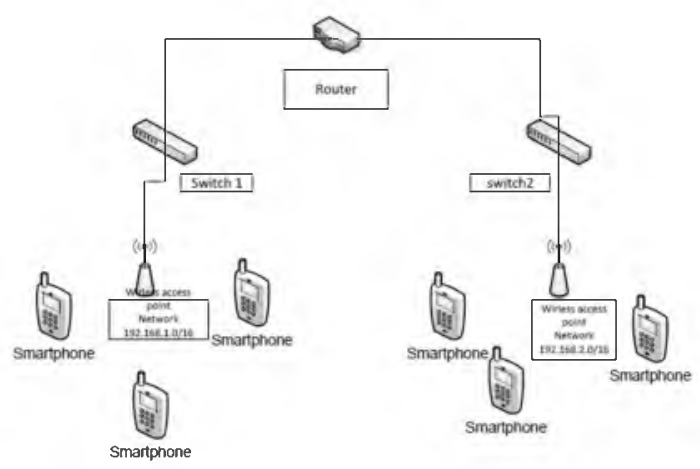

Gambar 7 Pengujian pertama
Pada pengujian yang kedua, digunakan sebuah laptop untuk Access point atau portable hostspot dengan menggunakan aplikasi connectifi yang di install. Portable hostspot memiliki fungsi sama seperti Wifi router dimana sebuah device atau laptop digunakan sebagai Access point. Gambar pengujian yang kedua ini dapat dilihat pada gambar 8. Uji coba ini menggunakan koneksi internet melalui modem yang digunakan pada sebuah laptop kemudian dijadikan Wifi router atau portable hotspot dengan menggunakan sebuah aplikasi tambahan yaitu connectifi melalui sebuah laptop untuk mengkoneksikan pada smartphone yang akan digunakan untuk menjalankan aplikasi Androtalky. Pada saat connectifi dijalankan maka sebuah laptop akan menjadi access point dengan seting IP address DHCP maka saat smartphone terkoneksi akan mendapat IP DHCP sehingga dapat menjalankan aplikasi Androtalky pada smartphone. 


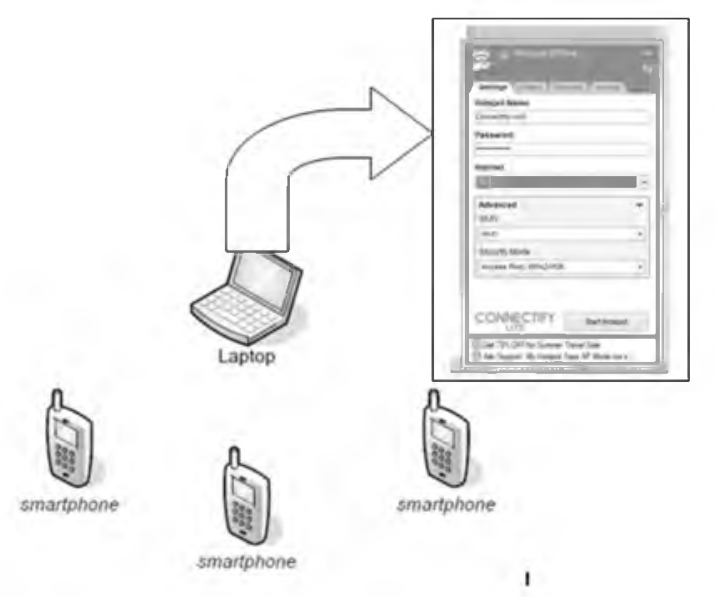

Gambar 8 Pengujian kedua

Pada pengujian yang ketiga jaringan yang digunankan berbeda dengan sebelumnya, perbedaannya yaitu memiliki kondisi dimana terdapat koneksi internet pada tempat yang berbeda dimana terdapat router 1 terdapat di tempat yang berbeda dengan router 2 dan 3 , dan memiliki jaringan yang berbeda. Gambar 9 menggambarkan skema jaringan pada router 1 , router 2 dan router 3 , memiliki jaringan yang berbeda yang terhubung pada sebuah jaringan public untuk melakukan komunikasi ping atau melakukan panggilan dengan metode ping melalui sebuah Personal Computer (PC) yang terdapat pada router 1 ke PC yang terdapat pada router 3 .

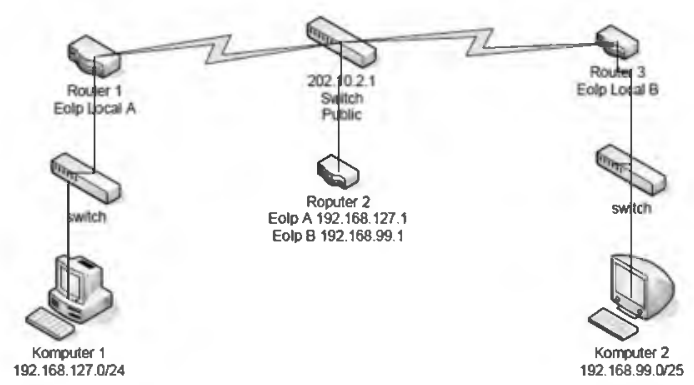

Gambar 9 Pengujian ketiga

\subsection{Pembahasan}

Pada pengujian pertama ini, aplikasi hasil rancangan digunakan pada lima buah smartphone yang terhubung ke Wireless Access Point (WAP). Ketika S1 mengirimkan sinyal audio dari penggunanya berupa sebuah kalimat hallo yang sebelumnya menekan tombol yang disediakan aplikasi untuk berbicara, suara yang bersumber dari $\mathrm{S} 1$ akan terdengar pada S2, S3, S4, S5, hal ini disebabkan smartphone berada pada jaringan dengan alamat jaringan yang sama dengan nomer port yang sama. Begitu juga dengan S2, ketika suara hallo bersumber dari S2 maka S1, S3, S4, S5, akan mendengarkan suara yang bersumber dari $\mathrm{S} 2$, dan seterusnya. Hasil pengujian dengan cara seperti ini dapat dilihat dan dibaca pada table 3 .

Tabel 3. Hasil Pengujian yang pertama

\begin{tabular}{|c|c|c|c|c|c|c|}
\hline No & $\mathrm{Pl}$ & \multicolumn{4}{|c|}{ P2 } & $\mathrm{K}$ \\
\hline 1. & S1 & $\mathrm{S} 2$ & S3 & S4 & S5 & \\
\hline 2. & $\mathrm{~S} 2$ & $\mathrm{~S} 1$ & S3 & S4 & S5 & \\
\hline 3. & S3 & $\mathrm{S} 1$ & S2 & $\mathrm{S} 4$ & S5 & \\
\hline 4. & S4 & $\mathrm{S} 1$ & S2 & $\mathrm{S3}$ & S5 & \\
\hline 5. & S5 & $\mathrm{S} 1$ & S2 & S3 & S4 & \\
\hline
\end{tabular}

Keterangan tabel

$\square \quad \mathrm{P} 1=$ Device Pengirim Suara

$\square \quad$ P2 $=$ Device Penerima Suara

$\square \mathrm{K}=$ Keterangan

Pada pengujian kedua, terdapat 3 buah smartphone (S) terhubung ke jaringan adhoc atau wireless network dengan alamat jaringan yang sama yang bersumber pada sebuah laptop kemudian S1 melakukan pengiriman data audio dengan cara seperti yang dilakukan pada pengujian pertama untuk 3 buah samrtphone dengan network dan port yang sama. Hasil pengujian seperti ini dapat dilihat dan dibaca pada tabel 4 .

Tabel 4. Hasil Pengujian yang kedua

\begin{tabular}{|l|l|l|l|l|}
\hline No & P1 & \multicolumn{2}{|c|}{ P2 } & K \\
\hline 1 & S1 & S2 & S3 & \\
\hline 2 & S2 & S1 & S3 & \\
\hline 3 & S3 & S1 & S2 & \\
\hline
\end{tabular}

Pengujian yang ketiga dengan menggunakan jaringan seperti yang terdapat pada gambar 4.3. Jaringan ini nantinya akan dimodifikasi dengan menggantikan PC yang ada pada gambar tersebut dengan WAP. Sebelum diganti dengan WAP, PC satu ke PC lainnya diuji komunikasi datanya dengan 
menggunakan ping dari $\mathrm{PC}$ yang terdapat pada router 1 ke PC yang terdapat pada router 3 yang memiliki jaringan yang berbeda dan tempat yang berjauhan kedua jaringan tersebut terhubung pada sebuah jaringan internet melalui IP Public, berikut beberapa gambar komunikasi ping dapat dilihat pada gambar 10 .

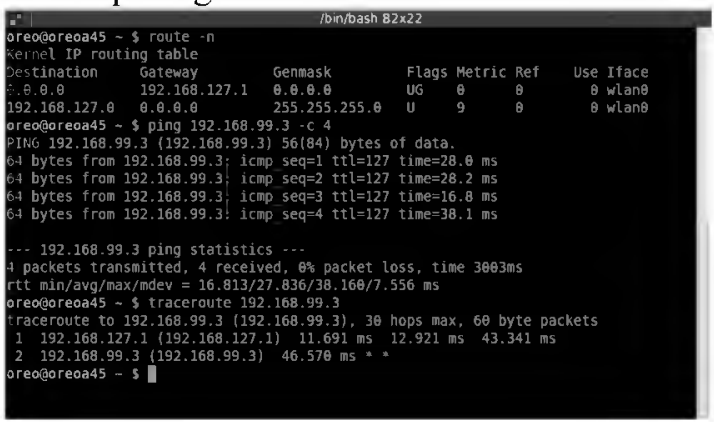

Gambar 10 Proses pengecekan komunikasi antar PC menggunakan ping dan traceroute

Pada gambar 10 dijelaskan bahwa sebuah PC1 dengan ip address 192.168.127.9/24 diberi sinyal ping ke PC2 yaitu dengan IP 192.168.99.3/24 dan hasilnya berupa reply yang berarti kedua $\mathrm{PC}$ terhubung melakukan komunikasi. Dari pengujan ketiga ini dimana memiliki Network yang berbeda maka aplikasi Androtalky dapat dilihat dan dibaca pada table 5 .

Tabel 5 Hasil Pengujian yang ketiga

\begin{tabular}{|l|l|l|l|}
\hline No & P1 & P2 & K \\
\hline 1 & S1 & S2 & \\
\hline 2 & S2 & S1 & \\
\hline
\end{tabular}

Dari hasil pengujian yang terlihat pada table 5 tersebut memperlihatkan ada komunikasi suara yang terjadi antara S1 dengan S2. Kualitas komunikasi satu arah untuk pengujian ini merupakan yang terendah dibanding dua pengujian sebelumnya.

\subsection{Perbandingan Androtalky Dengan Zello Walkie Talkie \\ Dari hasil penelitian sebelumnya yang} menggunakan Zello Walkie Talkie, tidak ditemukan data yang dapat digunakan perbandingan dengan Androtalky. Tetapi secara teknis perbandingan itu tetap ada.
Pada Zello Walkie Talkie dibutuhkan komputer yang digunakan sebagai server dari Zello Walkie Talkie yang dapat dihubungi oleh Zello Walkie Talkie versi androidnya. Sedangkan pada Andortalky tidak demikian, karena proses komunikasinya memanfaatkan socket dari setiap smartphone yang menggunakannya yang digunakan untuk mengirikan data rekaman suara kepada semua smartphone yang menggunakan Androtalky tersebut dalam satu arah.

4. Kesimpulan

1. Gelombang radio yang dipancar dan diterima oleh WAP dapat dimanfaatkan sebagai media telekomunikasi audio satu arah menggunakan smartphone berbasis android yang mempunyai fasilitas koneksi WiFi.

2. Kualitas audio dalam komunikasi yang menggunakan perangkat lunak androtalky tidak sebagus komunikasi audio yang berbasis provider pada peralatan telekomunikasi nirkabel generasi ketiga.

3. WAP yang dapat melayani komunikasi ini harus mampu memberikan alamat IP kepada setiap smartphone yang terhubung dan terhubung ke router agar dapat melayani komunikasi pada jaringan komputer dengan alamat jaringan yang berbeda.

5. Saran

1. Komunikasi di area jaringan lebih luas dapat terjadai jika ada konfigurasi pada jaringan komputer yang akan digunakan lebih baik lagi.

2. Perlu pengembangkan aplikasi berbasis multi platform yaitu pada smartphone dengan sistem operasi Windows Phone dan Mac os (apple).

\section{Ucapan Terima Kasih}

Penulis mengucapkan terima kasih kepada Sekolah Tinggi Teknologi Adisutjipto yang telah memberi dukungan finansial terhadap penelitian ini melalui pendanaan Penelitian Internal tahun 2016/2017. 
DAFTAR PUSTAKA

[1] Kasmad Ariansyah, Proyeksi Jumlah Pelanggan Telepon Bergerak Seluler di Indonesia, Buletin Pos dan Telekomunikasi, Vol.12, No.2, 2 Juni 2014, halaman 151-166

[2] Meria Octavianti, Slamet Mulyana, Penggunaan Aplikasi Zello Walkie Talkie sebagai Media Pengungkapan Diri antara Sesama Sopir Taksi Online di Kota Bandung, Jurnal Politikom Indonesiana Vol. 2 No. 1 Juli 2017

[3] Denis, Alan, Barbara Haley Wixon dan David Tagarrden. 2012. Systems Analysis and Design with UML Version 2.0: An Object-Oriented Approach Second Edition. Wiley.

[4] Safaat, H. Nazrudin. 2012. Pemrograman Aplikasi Mobile Smartphone dan Tablet PC Berbasis Android.Informatika. Bandung

[5] Whitten L Jeffery, Bentley D. Lonnie, Dittman C. Kevin, 2004, Metode Desain dan Analisis Sistem, Edisi 6., Edisi Internasional Mc.Graw Hill Education dan Penerbit Andi Jogjakarta

[6] Kobryn, Cris, Grady Booch dan Ivar Jacobson. 2005. UML Distilled Panduan Singkat Bahasa Pemodelan Objek Standar.Andi Publisher. Yogyakarta.

[7] Eriko Darmawan G, 2010,
Pemograman Dasar $\quad$ C - Java C\# yang susah jadi mudah!!, Bandung

[8] Coulouris, 2012, "Distributed Systems Concepst and Design", Fifth Edition, Addison-Wesley, Boston, Massachusetts

[9] http://www.internetworldstats.com/asi a/id.htm diakses tanggal 11 September 2017

[10] http://momototoy.com/pengertianhandy-talky/ diakses tanggal 12 September 2017

[11] https://tekno.tempo.co/read/news/201 3/01/20/172455638/ponsel-ini-bisaberfungsi-sebagai-walkie-talkie diakses tanggal 12 September 2017

[12] http://tekno.kompas.com/read/2015/0 2/10/14050057/Menyimak. Teknologi. Seluler.dari.1G.Hingga.4G diakses tanggal 12 Oktober 2017

[13] https://en.wikipedia.org/wiki/Motorol a DynaTAC diakses tanggal 12 Oktober 2017

[14] http://tekno.kompas.com/read/2014/0 4/30/1033082/11.Ponsel.Nokia.yang. Melegenda diakses tanggal 12 Oktober 2017

[15] http://www.macworld.co.uk/review/ip hone/apple-iphone-se-review-2017uk-3625110/ diakses tanggal 12 Oktober 2017

[16] http://www.cyberhousecafe.net/comp uters/networking.htm diakses tanggal 12

Oktober 2017 